\title{
Influence of clenbuterol treatment during six weeks of chronic right ventricular pressure overload as studied with pressure-volume analysis
}

Jimmy K. F. Hon, MB, ChB ${ }^{a}$

Paul Steendijk, $\mathrm{PhD}^{\mathrm{b}}$

Mario Petrou, FRCS

Kit Wong, FRCS a

Magdi H. Yacoub, FRS

From the Department of Cardiothoracic Surgery, ${ }^{\mathrm{a}}$ National Heart and Lung Institute at Royal Brompton Hospital, London, United Kingdom, and the Department of Cardiology, ${ }^{\mathrm{b}}$ Leiden University Medical Center, Leiden, The Netherlands.

This study was supported by the British Heart Foundation project grant PG/98079.

Received for publication July 26, 2000; revisions requested Nov 15, 2000; revision received Dec 11, 2000; accepted for publication Jan 17, 2001.

Address for reprints: Professor Sir Magdi Yacoub, Department of Cardiothoracic Surgery, Royal Brompton Hospital, Sydney Street, London SW3 6NP, United Kingdom (E-mail: j.hon@ic.ac.uk).

J Thorac Cardiovasc Surg 2001;122:767-74

Copyright (C) 2001 by The American Association for Thoracic Surgery

$0022-5223 / 2001 \$ 35.00+0 \quad \mathbf{1 2 / 1 / 1 1 4 3 5 4}$

doi:10.1067/mtc.2001.114354
Objectives: Chronic pressure overload cardiac hypertrophy produces ventricular dysfunction. There is evidence that clenbuterol, a $\beta_{2}$-adrenoceptor agonist, produces cardiac hypertrophy with preserved function in rodents. We sought to determine the cardiac hypertrophic effects of clenbuterol on the thin-walled ventricles of large animals undergoing chronic pressure overload by means of pulmonary artery banding.

Methods: Right ventricular pressure-volume loops were obtained in open-chest sheep before and after $6 \frac{1}{2}$ weeks of pulmonary artery banding by using micromanometer conductance catheters. Animals were randomly assigned to treatment with either saline solution $(n=7)$ or clenbuterol $(n=8)$. Treatment was started immediately after pulmonary artery banding.

Results: Acute pulmonary artery banding increased the right ventricular systolic pressure equally in both groups (saline group, $23.9 \pm 3.3$ to $48.1 \pm 9.7 \mathrm{~mm} \mathrm{Hg}$; clenbuterol group, $24.3 \pm 2.8$ to $48.6 \pm 10.7 \mathrm{~mm} \mathrm{Hg}$ [mean \pm standard deviation]). Six weeks of treatment produced no significant differences in the body weight, heart weight, heart/body weight ratio, right ventricular wall thickness, heart rate, and stroke volume between the groups. However, the slope of the end-systolic pressurevolume relation and the slope of the first derivative of the right ventricular developed pressure/end-diastolic volume relation were significantly increased when compared with baseline values in clenbuterol-treated animals but not in saline-treated animals.

Conclusion: Clenbuterol treatment during pulmonary artery banding improves systolic function of the chronically pressure-overloaded right ventricle. This has important implications for the use of pharmacologic agents in modulating cardiac adaptation.

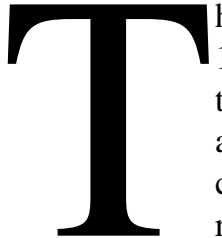

he 2-stage arterial switch operation (ASO) was first described in $1977^{1}$ and is now rarely used, except in patients with transposition of the great arteries (TGA) and intact ventricular septum presenting after the neonatal period ${ }^{2}$ and in situations in which the right ventricle has failed after a previous atrial switch operation. ${ }^{3,4}$ Recent revival of interest in this technique has stemmed from the published long-term results of inflow correction operations (Senning and Mustard operations) for TGA, which showed progressive right ventricular dysfunction over time, ${ }^{5,6}$ suggesting that a significant proportion of these patients will require surgical intervention, probably in the form of the 2-stage ASO. The first stage of the 2-stage ASO involves pulmonary artery banding $(\mathrm{PAB})$ to create pressure overload cardiac hyper- 


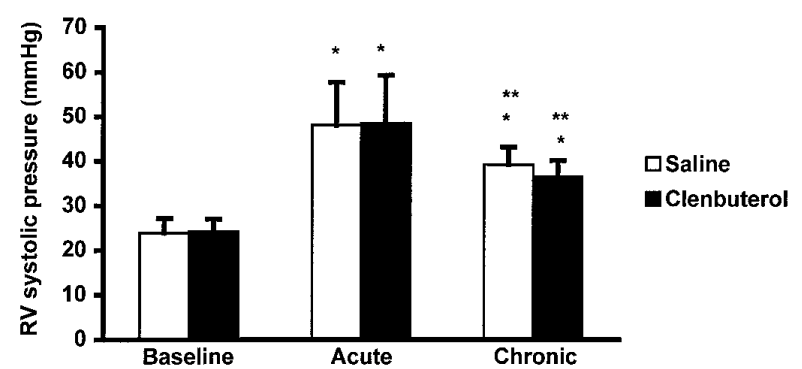

Figure 1. Effects of PAB on right ventricular systolic pressure. There is no difference in the right ventricular systolic pressure at the 3 time points recorded. However, the pressures at the chronic stage are lower than those recorded at the acute stage in both groups. ${ }^{*} \boldsymbol{P}<.001$ versus baseline; ${ }^{*} \boldsymbol{P}<.05$ versus acute stage.

trophy in the thin-walled, low-pressure morphologically left ventricle. However, cardiac hypertrophy induced by pressure overload has been known to be initially compensatory to normalize wall stress but eventually leads to ventricular dysfunction and heart failure, as illustrated by the increased morbidity and mortality in hypertensive heart disease in the presence of cardiac hypertrophy. ${ }^{7}$ For the same reason, deterioration of left ventricular function has been reported, particularly in older children at medium-term follow-up after the 2-stage ASO. 8,9

Hence, the induction of physiologic cardiac hypertrophy without adverse effect, like that achieved with exercise training, ${ }^{10}$ is desirable in cardiac operations. Clenbuterol, a selective $\beta_{2}$-adrenergic receptor agonist, has been shown to induce cardiac hypertrophy in rats with molecular and functional parameters consistent with those of physiologic cardiac hypertrophy. ${ }^{11,12}$ In addition, attenuation of the pathologic molecular and functional characteristics of pressure-overload left ventricular hypertrophy induced by clenbuterol has also been reported..$^{13}$ These reports on clenbuterol have been supported by communications from various groups reporting the beneficial functional effects of $\beta_{2}$-adrenergic receptor overexpression in mice hearts. ${ }^{14-16}$ The study by Liggett and associates ${ }^{14}$ in particular showed that the positive effects of $\beta_{2}$-adrenergic receptor overexpression on cardiac function was present at 1 year as long as a certain threshold for spontaneous receptor activation was not exceeded.

The effects of clenbuterol on thin-walled, low-pressure ventricles, such as those seen in the morphologically left ventricle in TGA, have not been studied. There is also a lack of information on the cardiac effects of clenbuterol in large mammalian species. Small animal hearts are different from those of large animals both functionally and at the molecular level. For example, in small animals the $\alpha$ cardiac myosin heavy chain constitutes close to $90 \%$ of total cardiac myosin heavy chain, whereas in human subjects it constitutes only $10 \%$.
The aim of the current study is to test the hypothesis that clenbuterol, when given at the time of induction of pressureoverload cardiac hypertrophy in the right ventricles of sheep by means of $\mathrm{PAB}$, improves right ventricular systolic function. Banding of the pulmonary artery will simulate the hemodynamic condition in the first stage of the 2-stage ASO, during which banding is performed to induce hypertrophy in the thin-walled, low-pressure morphologically left ventricle.

\section{Methods}

Fifteen Dorset Down sheep with a body weight of $23.53 \pm 5.30 \mathrm{~kg}$ (mean $\pm \mathrm{SD}$ ) were cared for in accordance with the guidelines laid down by the Home Office of Great Britain and Northern Ireland (1986). All were given food and water ad libitum and underwent 1 to 2 weeks of settlement before any procedures were performed.

\section{Surgical Preparation}

Premedication with ketamine (100-150 mg) and diazepam (10 mg) were administered intramuscularly. General anesthesia was induced with inhalation of halothane and maintained by means of intubation and ventilation with a mixture of oxygen (49.5\%), nitrous oxide $(49.5 \%)$, and halothane $(1 \%)$ with a standard ventilator (Harvard Apparatus, Inc, Holliston, Mass). Muscle relaxants were omitted. A $6 \mathrm{~F}$ thermodilution catheter was introduced into the right side of the heart through the left jugular vein for central venous pressure, pulmonary artery pressure, and cardiac output measurements. The left carotid artery was cannulated for systemic arterial pressure monitoring. The ruminant stomach was decompressed with a 12-bore orogastric tube. Arterial oxygen saturation was monitored with a pulse oximeter and maintained at $90 \%$ to $100 \%$. Ringer's lactate solution was infused into a peripheral vein throughout the study at 1 to $2 \mathrm{~mL} \cdot \mathrm{kg}^{-1} \cdot \mathrm{h}^{-1}$ and occasionally supplemented with sodium bicarbonate to maintain a near-normal base deficit. PAB was performed through a left thoracotomy incision, and the pericardium was opened fully. Inflow reduction to the heart during generation of the end-systolic pressure-volume relation was achieved by lifting a nylon tape passed around the inferior vena cava for no more than 8 seconds. Left atrial pressure was measured directly by using a fluid-filled manometer with a 14gauge hypodermic needle. A 5F, 12-electrode (5 mm of interelectrode distance) combined micromanometer conductance catheter (Millar Instruments, Inc, Houston, Tex) was inserted into the right ventricle through a purse-string suture at the top of the right ventricular outflow tract, just below the pulmonary valve. The conductance catheter was then connected to a signal conditioner processor (Leycom Sigma5-DF, CD Leycom, Zoetermeer, The Netherlands) to convert instantaneous conductance measurements into volume. All analogue signals were digitized with 12-bit accuracy on an IBM-compatible personal computer at a sampling rate of $200 \mathrm{~Hz}$ and saved on a hard disk for subsequent analysis.

The application, validation, and calibration of the conductance technique for measuring ventricular volume was described elsewhere. ${ }^{17}$ Although originally designed for use in the left ventricle, the feasibility of conductance catheter measurements in the right ventricle has recently been demonstrated. ${ }^{18-20}$ 
TABLE 1. General hemodynamics

\begin{tabular}{|c|c|c|c|c|c|c|}
\hline & \multicolumn{2}{|c|}{ Baseline } & \multicolumn{2}{|c|}{ Acute } & \multicolumn{2}{|c|}{ Chronic } \\
\hline & Saline & Clenbuterol & Saline & Clenbuterol & Saline & Clenbuterol \\
\hline Heart rate (beats/min) & $114 \pm 16$ & $116 \pm 23$ & $127 \pm 19$ & $133 \pm 20$ & $106 \pm 28$ & $121 \pm 18$ \\
\hline Systolic arterial blood pressure $(\mathrm{mm} \mathrm{Hg})$ & $78 \pm 9$ & $82 \pm 11$ & $72 \pm 8$ & $76 \pm 11$ & $75 \pm 8$ & $81 \pm 13$ \\
\hline RV/LV systolic pressure ratio & $0.31 \pm 0.03$ & $0.30 \pm 0.03$ & $0.66 \pm 0.10^{*}$ & $0.64 \pm 0.08^{*}$ & $0.53 \pm 0.07^{*} \dagger$ & $0.46 \pm 0.11^{*} \dagger$ \\
\hline RV systolic pressure $(\mathrm{mm} \mathrm{Hg})$ & $24 \pm 3$ & $24 \pm 3$ & $48 \pm 10^{*}$ & $49 \pm 11^{*}$ & $39 \pm 4^{*} \dagger$ & $37 \pm 4^{*} \dagger$ \\
\hline Central venous pressure $(\mathrm{mm} \mathrm{Hg})$ & $8.6 \pm 2.8$ & $8.1 \pm 1.1$ & $12.9 \pm 2.3^{*}$ & $12.4 \pm 1.9^{*}$ & $11.1 \pm 2.7^{*}$ & $12.3 \pm 3.8^{*}$ \\
\hline Left atrial pressure $(\mathrm{mm} \mathrm{Hg})$ & $4.4 \pm 2.1$ & $4.4 \pm 0.9$ & $3.9 \pm 1.6$ & $3.6 \pm 0.9$ & $4.4 \pm 1.0$ & $3.8 \pm 1.0$ \\
\hline
\end{tabular}

No significant differences between the saline and clenbuterol groups were found at any stage (ie, baseline, acute, or chronic). $R V$, Right ventricle; $L V$, left ventricle.

${ }^{*} P<.05$ versus baseline.

$\dagger P<.05$ versus acute stage.

\section{Study Protocol}

Once the conductance catheter was in the optimal position, a 15minute period was allowed for the animal to reach hemodynamic stability. Right ventricular pressure-volume loops during steady state, preload reduction, cardiac output measurements (with the thermodilution technique), and hypertonic saline injection (for measurement of parallel conductance) were then obtained at baseline before PAB. All measurements were taken at end-expiration with the ventilator turned off. The pulmonary artery band was adjusted to maximum tolerable tightness by not allowing the systolic arterial blood pressure to fall below $60 \mathrm{~mm} \mathrm{Hg}$ at any time during the experiment. Further tightening of the band resulted in severe bradycardia and rapid decline in systemic arterial blood pressure, which normalized when the band was released immediately. All catheters were then removed, and the chest was closed. After successful PAB, the sheep were randomly assigned to 2 groups: the saline treatment group $(n=7)$ and the clenbuterol treatment group $(\mathrm{n}=8)$.

On the first postoperative day, the sheep were treated with either $2 \mathrm{~mL}$ of saline solution or $0.5 \mathrm{mg} / \mathrm{kg}$ clenbuterol (Boehringer-Ingelheim, Berkshire, United Kingdom), administered by means of once daily subcutaneous injection, for a total duration of 6 weeks. Injections were stopped 3 days before the restudy as a wash-out period to avoid any direct inotropic effect of clenbuterol on the myocardium, thus allowing us to assess the true intrinsic myocardial pump function.

Restudy was performed by using exactly the same technique through a median sternotomy. Animals were put to death at the end of the experiment by means of exsanguination while the heart was harvested. After the PAB had been identified, the great vessels were trimmed away, and the hearts were weighed and examined for right ventricular and left ventricular wall thickness by using a pair of vernier calipers (measurements taken at the base of the anterior papillary muscle and middle of the septum). Wall thickness measurements were taken 3 times, and the average was calculated. The right ventricular free wall was not weighed separately.

\section{Data and Statistical Analysis}

Analysis of the pressure-volume loops was achieved by using a customized software package. Three load-independent indices of systolic function were used in this study to quantify right ventricular performance: slope of the end-systolic pressure-volume relation (Ees); slope of the first derivative of the right ventricular pressure-end diastolic volume relation $\left(\mathrm{dp} / \mathrm{dt}_{\max }-\mathrm{Ved}\right)$, and the preload recruitable stroke work relation (PRSW). Within-group analysis of all parameters was performed by using the paired Student $t$ test. All between-group analyses were performed by using the unpaired Student $t$ test. All results shown in the text and tables are expressed as means $\pm \mathrm{SD}$.

\section{Results \\ Hemodynamic Data}

Acute right ventricular peak systolic pressure after PAB (saline group, $48.1 \pm 9.7 \mathrm{~mm} \mathrm{Hg}$; clenbuterol group, $48.6 \pm$ $10.7 \mathrm{~mm} \mathrm{Hg} ; P=.93$ ) and at the $6 \frac{1}{2}$-week chronic stage (saline group, $39.3 \pm 3.9 \mathrm{~mm} \mathrm{Hg}$; clenbuterol group, $36.5 \pm$ $3.7 \mathrm{~mm} \mathrm{Hg} ; P=.18$ ) were not different between the 2 groups (Figure 1). The response of the various hemodynamic variables to PAB is presented in Table 1 . PAB produced no significant changes to the heart rate and left atrial pressure in both groups, suggesting that the bands were not excessively tight, nor was there any difference seen in any of the parameters between the 2 groups. The right ventricular systolic pressure and right ventricular/left ventricular systolic pressure ratio in both groups rose significantly after PAB when compared with baseline values. At the chronic stage, both variables were significantly reduced when compared with the corresponding values at the acute stage but remained significantly elevated compared with baseline values.

\section{Weight and Wall Thickness}

Sheep in both groups continued to grow after PAB. Although the saline-treated animals started with a slightly lower mean baseline body weight, there was no significant difference between the 2 groups (Table 2). Six weeks of clenbuterol treatment produced no significant difference in the mean body weight increase, heart weight, heart/body weight ratio, and interventricular septum thickness between 
TABLE 2. Characteristics of saline- and clenbuterol-treated sheep

\begin{tabular}{lcc}
\hline & Saline & Clenbuterol \\
\hline Mean baseline body weight $(\mathrm{kg})$ & $22.21 \pm 6.15$ & $24.69 \pm 4.53$ \\
Mean body weight increase $(\mathrm{kg})$ & $6.07 \pm 2.59$ & $6.44 \pm 3.58$ \\
Heart weight $(\mathrm{g})$ & $204.2 \pm 18.8$ & $212.0 \pm 22.2$ \\
Heart/body weight ratio $\left(\times 10^{-3}\right)$ & $7.59 \pm 1.56$ & $6.98 \pm 1.07$ \\
RV wall thickness $(\mathrm{mm})$ & $7.4 \pm 0.8$ & $8.1 \pm 0.9$ \\
RV/LV wall thickness ratio & $0.67 \pm 0.08$ & $0.76 \pm 0.10$ \\
Interventricular septum thickness $(\mathrm{mm})$ & $9.4 \pm 1.4$ & $9.4 \pm 1.2$ \\
RV wall thickness/Ved ratio $(\mathrm{mm} / \mathrm{mL})$ & $0.23 \pm 0.08$ & $0.29 \pm 0.19$
\end{tabular}

$P$ values are not significant. $R V$, Right ventricle; $L V$, left ventricle; $V e d$, right ventricular end-diastolic volume.

TABLE 3. RV volumetric data

\begin{tabular}{|c|c|c|c|c|}
\hline & \multicolumn{2}{|c|}{ Baseline } & \multicolumn{2}{|c|}{ Chronic } \\
\hline & Saline & Clenbuterol & Saline & Clenbuterol \\
\hline $\mathrm{RV}$ end-diastolic volume (mL) & $22.4 \pm 8.2$ & $31.4 \pm 14.7$ & $33.9 \pm 8.9$ & $40.8 \pm 29.1$ \\
\hline RV end-systolic volume (mL) & $10.9 \pm 3.9$ & $17.8 \pm 11.1$ & $22.0 \pm 9.3$ & $28.1 \pm 26.4$ \\
\hline $\mathrm{RV}$ indexed end-diastolic volume $(\mathrm{mL} / \mathrm{kg})$ & $0.97 \pm 0.18$ & $1.26 \pm 0.49$ & $1.31 \pm 0.54$ & $1.36 \pm 0.98$ \\
\hline RV indexed end-systolic volume $(\mathrm{mL} / \mathrm{kg})$ & $0.47 \pm 0.10$ & $0.70 \pm 0.40$ & $0.85 \pm 0.42$ & $0.95 \pm 0.88$ \\
\hline RV stroke volume $(\mathrm{mL})$ & $12.0 \pm 5.0$ & $15.1 \pm 5.0$ & $13.8 \pm 2.7$ & $13.5 \pm 4.5$ \\
\hline RV ventricular output (mL/min) & $1303.2 \pm 450.3$ & $1844.5 \pm 580.0$ & $1604.0 \pm 443.6$ & $1843.9 \pm 685.5$ \\
\hline RV ejection fraction (\%) & $53.1 \pm 9.3$ & $52.2 \pm 13.8$ & $42.0 \pm 8.3$ & $42.4 \pm 22.9$ \\
\hline
\end{tabular}

$P$ values are not significant. $R V$, Right ventricle; $L V$, left ventricle.

the 2 groups of animals (Table 2). There was, however, an incremental trend in the right ventricular wall thickness, the right ventricular/left ventricular wall thickness ratio (saline group, $0.67 \pm 0.08$; clenbuterol group, $0.76 \pm 0.10 ; P=.07$ ), and the right ventricular wall thickness/end-diastolic volume ratio in the clenbuterol-treated animals, although these parameters did not reach statistical significance.

\section{Volumetric Data}

Conductance-derived volumetric data presented in Table 3 showed that mean end-diastolic and end-systolic volumes were slightly (but not significantly) larger in the clenbuterol-treated animals, possibly related to their slightly higher body weight. There was a greater tendency for both the end-diastolic volumes (saline group, 51\% increase; clenbuterol group, $30 \%$ increase) and the end-systolic volumes (saline group, 102\% increase; clenbuterol group, 58\% increase) to increase after banding in saline-treated animals compared with that seen in clenbuterol-treated animals, although this did not reach statistical significance. This tendency was further exaggerated after indexing the volumes to body weight (indexed end-diastolic volume: saline group, $35 \%$ increase; clenbuterol group, $8 \%$ increase; indexed endsystolic volume: saline group, 79\% increase; clenbuterol group, $35 \%$ increase). Correspondingly, no significant change to the right ventricular stroke volumes and right ventricular output were seen in either group.

\section{Right Ventricular Systolic Function}

Data for right ventricular systolic function are shown in Figure 2, $A$ and $B$, and Table 4 . The Ees and the $\mathrm{dp} / \mathrm{dt}_{\max ^{-}}$ Ved were increased significantly when compared with baseline in animals that were treated with clenbuterol but not in those that were treated with saline solution (Ees: saline group, $2.38 \pm 0.42$ to $3.40 \pm 0.69 \mathrm{~mm} \mathrm{Hg} / \mathrm{mL}, P=.47$; clenbuterol group, $1.82 \pm 0.51$ to $5.68 \pm 0.90 \mathrm{~mm} \mathrm{Hg} / \mathrm{mL}, P=$ $.01 ; \mathrm{dp} / \mathrm{dt}_{\max }-$ Ved: saline group, $11.18 \pm 9.25$ to $12.11 \pm$ $3.71 \mathrm{~mm} \mathrm{Hg} \cdot \mathrm{mL}^{-1} \cdot \mathrm{s}^{-1}, P=.74$; clenbuterol group, $8.82 \pm$ 4.38 to $\left.20.0 \pm 7.74 \mathrm{~mm} \mathrm{Hg} \cdot \mathrm{mL}^{-1} \cdot \mathrm{s}^{-1}, P=.01\right)$. This is evidence for improvement in right ventricular systolic function after clenbuterol treatment. Analysis of the third load-independent index PRSW showed that clenbuterol-treated animals demonstrated a $32 \%$ greater increase compared with that seen in the saline group, although this increase did not reach statistical significance.

\section{Discussion}

The present study shows that the $\beta_{2}$-adrenergic receptor agonist clenbuterol improves the systolic function of the thin-walled, low-pressure right ventricle of sheep after $6 \frac{1}{2}$ weeks of PAB. The highly significant improvement in function was reflected by a $212 \%$ increase in Ees in the clenbuterol group compared with a $43 \%$ increase in the saline group. This is illustrated in Figure 3. Similar evidence came from $\mathrm{dp} / \mathrm{dt}_{\max }-$ Ved, in which there was a $127 \%$ increase in 


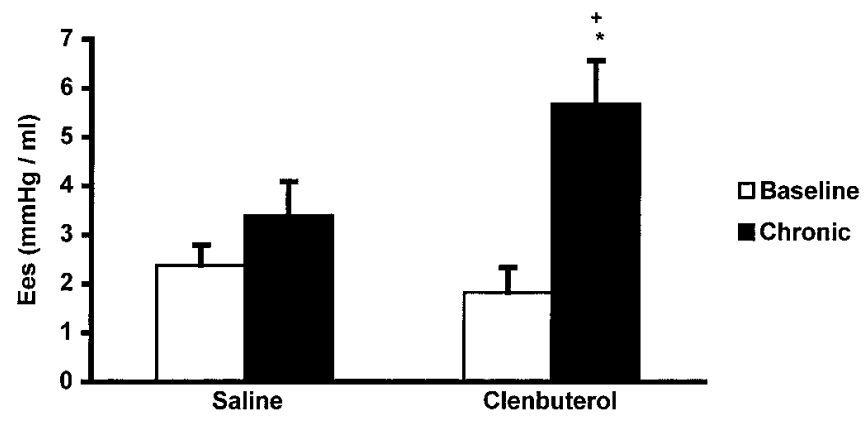

A

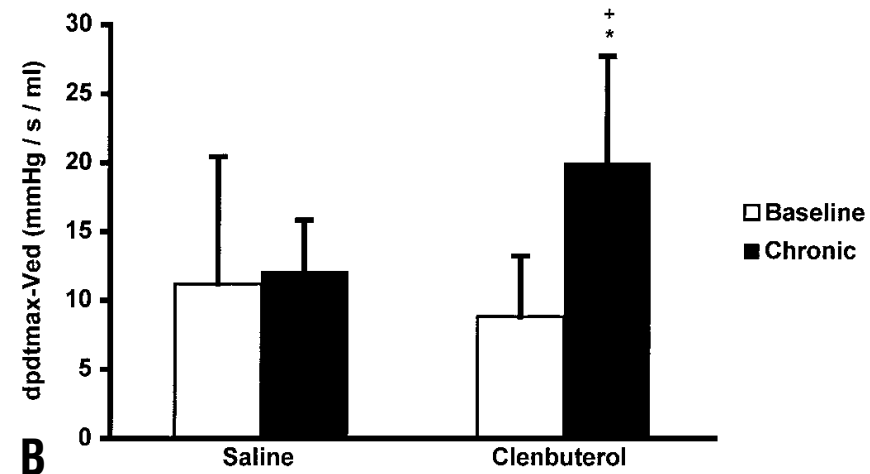

Figure 2. Indices of systolic ventricular function. $A$, Ees; $B$, dp/dtmax-Ved. ${ }^{*} P=.01$ versus baseline; $+P<.05$ versus saline treatment.

the clenbuterol group compared with the corresponding value of $8 \%$ in the saline group. The technique used in the current study has been known to be a relatively loadindependent way of assessing ventricular function. However, the usefulness of the Ees to characterize ventricular contractility has been put into doubt by some investigators in recent years because of evidence of afterload dependency. ${ }^{21,22}$ Our study results could not have been affected by this dependence on afterload because the increase in afterload in both groups both acutely and after $6 \frac{1}{2}$ weeks of banding (as reflected by the right ventricular peak systolic pressure at both time points) were not significantly different from each other. Any afterload dependency would have affected both groups equally. De Vroomen and colleagues ${ }^{20}$ reported an increase in Ees of more than 50\% shortly after acute right ventricular pressure overload. In the current study the acute increase in right ventricular afterload is greater than that reported by de Vroomen and colleagues. However, the Ees in the saline-treated animals is less than that reported by these authors, suggesting that right ventricular function may have deteriorated since banding took place. It can be concluded that the modest $43 \%$ increase in Ees in the saline group is the result of a combination of afterload-induced improvement in contractility (homeometric autoregulation), ventricular dysfunction, and other common features present in both groups. Any further increase in Ees beyond this point, as seen in the clenbuterol group, must be due to the effect of clenbuterol. As a result of improved contractility, clenbuterol-treated animals were relying more on their intrinsic pump property and less on the FrankStarling mechanism to overcome the increased afterload resistance. In contrast, in the saline-treated animals stroke volumes and ventricular outputs were maintained at the expense of a greater degree of ventricular dilation. If the clenbuterol-treated animals were allowed to increase their preload to the degree seen in the saline-treated animals, the highly load-dependent parameters, such as stroke volumes and ventricular outputs, would be significantly increased. In contrast to Ees and dp/dt $\max ^{-V e d, ~ P R S W ~ d i d ~ n o t ~ s h o w ~ a ~ s i g-~}$ nificant increase in the clenbuterol group, although there was an incremental trend toward increase. This could be explained by the less sensitive nature of this index for detecting changes in systolic contractility among the 3 indices reported here ${ }^{23}$ because PRSW describes the entire cardiac cycle rather than reflecting pure systolic property.

However, we cannot exclude the possibility that pathologic changes may develop if treatment is prolonged beyond 6 weeks nor can we predict the longevity of this improved function when treatment is discontinued for a longer period of time than the 3 days in the current study. Nevertheless, the ability of clenbuterol to augment the systolic function of the chronically pressure-overloaded thin-walled ventricle is potentially desirable in various surgical settings. Pharmacological modulation of hypertrophy may improve surgical outcome, particularly that of the 2-stage ASO for the TGA, by reducing the degree of hypertrophy and pressure overload needed and by preserving ventricular function. The potential use of clenbuterol may be further optimized by starting treatment several weeks before PAB to counter acute ventricular failure, which is a common reason for unsuccessful banding in TGA. However, in our study starting clenbuterol early would not have allowed us to measure the true baseline contractility because of direct $\beta$ adrenergic stimulation on the heart. In addition, starting clenbuterol treatment before band placement might have led to different degrees of band tightness in the 2 groups, hence making the final assessment of ventricular systolic function difficult to interpret.

It is generally accepted that chronic stimulation with sympathomimetic agents has deleterious effects on myocardial function that is associated with poor outcome. ${ }^{24}$ This concept is further illustrated by the benefits of $\beta$ adrenergic receptor blockade in heart failure. ${ }^{25}$ However, Liggett and coworkers, ${ }^{14}$ and previously Milano and col- 

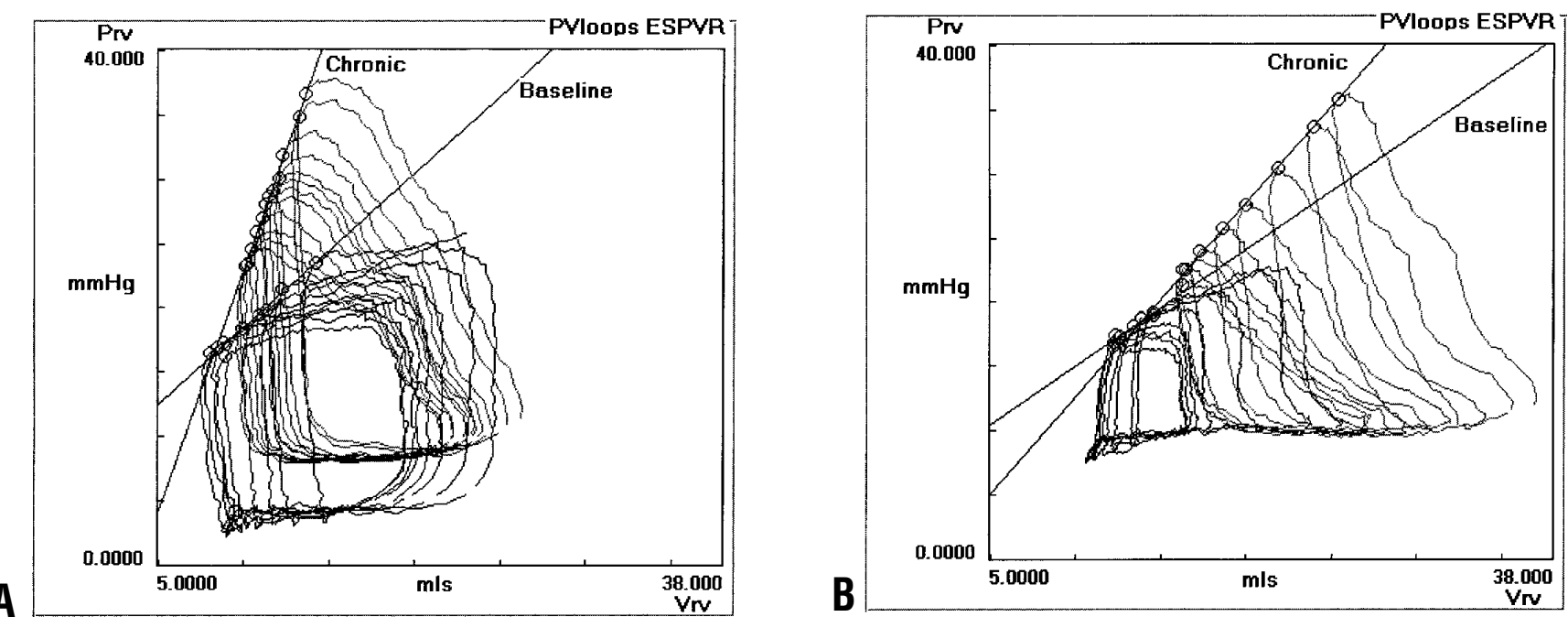

Figure 3. Typical example of the pressure-volume loops obtained at baseline and at chronic stage: clenbuteroltreated animal (A) and saline-treated animal (B). Notice the increase in slope between the 2 time points is more marked in the clenbuterol-treated animal.

leagues, ${ }^{15}$ have shown in transgenic mice that increased $\beta_{2^{-}}$ adrenergic receptor expression and activity is in fact beneficial to ventricular function. Liggett and colleagues ${ }^{14}$ showed that this is true as long as the level of receptor overexpression does not exceed that for spontaneous activation, which in their experiment was between 150 and 350 times the background $\beta_{2}$-adrenergic receptor expression. Furthermore, they have also demonstrated that the hearts tolerated enhanced contractile function caused by 60 -fold $\beta_{2}$-adrenergic receptor overexpression without detriment for a period of at least 1 year. Our current results in sheep are in direct agreement with their findings, suggesting that not only the beneficial effects of $\beta_{2}$-adrenergic receptor stimulation on ventricular function in mice is reproducible in the large animal species but also that clenbuterol is able to modulate an otherwise pathologic hypertrophy process into one that is more physiologic in nature, as illustrated by the improved systolic function and the $26.1 \%$ greater wall thickness/end-diastolic volume ratio (Table 2). In the current report clenbuterol treatment was initiated on the day after the initial operation, and function was assessed again only at the end of the 6-week treatment period. Hence, it is not possible to know whether this modulation process is achieved by stimulating physiologic cardiac growth from the outset or by transforming pathologic cardiac growth into physiologic growth sometime during the experimental period. Although in the current study we do not know the effect of clenbuterol in animals that have not undergone PAB, previous reports by Petrou, ${ }^{12}$ Wong, ${ }^{11}$ and their colleagues showed conclusively that clenbuterol can stimulate left ventricular hypertrophy in the absence of pressure overload with normal ventricular function and physiologic molecular phenotype (eg, elevated levels of mRNA to atrial natriuretic factor without a concomitant increase in skeletal $\alpha$ actin and $\beta$ myosin heavy chain and normal expression of sarcoplasmic reticulum $\mathrm{Ca}^{2+}$-ATPase2a (SERCA2a), phospholambin mRNA and collagen in an otherwise healthy normal rat heart. Furthermore, Wong and colleagues ${ }^{13}$ documented the ability of clenbuterol to modulate the pathologic morphology, molecular markers, and functional phenotype of the pressure-overloaded hypertrophied left ventricles toward normality (eg, improvements in the sarcoplasmic reticulum $\mathrm{Ca}^{2+}$-ATPase2a mRNA levels and normal collagen concentrations in clenbuterol-treated hearts). In the latter study, pressure overload to the left ventricle was achieved by banding of the ascending aorta, and Wong and colleagues ${ }^{13}$ observed that clenbuterol produced a specific form of cardiac hypertrophy with improved ventricular function and normal collagen concentration. Clenbuterol, however, produced only a modest (and nonsignificant) increase in the left ventricular mass index in excess of that already caused by banding alone (11\%). This is in direct agreement with our current data on ventricular wall thickness and function. The dose of $0.5 \mathrm{mg} / \mathrm{kg}$ used in this study was based on our previous work, ${ }^{26}$ although no formal clinical dose-response trials have been performed. Recently published skeletal muscle data from work performed on goats suggested that smaller oral doses (450 $\mu \mathrm{g} / \mathrm{wk})$ used for human subjects were equally effective in enhancing muscle function. ${ }^{27}$ In our current study it would seem that 6 weeks of clenbuterol treatment was effective in producing significant improvement in systolic function. Hence, tachyphylaxis, even if present, does not seem to cause any limitation to its use in this context. 
TABLE 4. RV systolic indices

\begin{tabular}{|c|c|c|c|c|}
\hline & \multicolumn{2}{|c|}{ Baseline } & \multicolumn{2}{|c|}{ Chronic } \\
\hline & Saline & Clenbuterol & Saline & Clenbuterol \\
\hline RV Ees $(\mathrm{mm} \mathrm{Hg} / \mathrm{mL})$ & $2.38 \pm 0.42$ & $1.82 \pm 0.51$ & $3.40 \pm 0.69$ & $5.68 \pm 0.90^{*} \dagger$ \\
\hline$r^{2}-r$ & 0.95 & 0.92 & 0.98 & 0.82 \\
\hline $\mathrm{V}_{40}(\mathrm{~mL})$ & $23.07 \pm 8.86$ & $35.26 \pm 19.91$ & $27.42 \pm 8.82$ & $30.29 \pm 25.64$ \\
\hline $\mathrm{RV} \mathrm{dp} / \mathrm{dt}_{\max }-\mathrm{Ved}\left(\mathrm{mm} \mathrm{Hg} \cdot \mathrm{mL}^{-1} \cdot \mathrm{s}^{-1}\right)$ & $11.18 \pm 9.25$ & $8.82 \pm 4.38$ & $12.11 \pm 3.71$ & $20.0 \pm 7.74^{*} \dagger$ \\
\hline 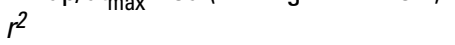 & 0.65 & 0.6 & 0.54 & 0.59 \\
\hline $\mathrm{V}_{300}(\mathrm{~mL})$ & $31.07 \pm 12.58$ & $35.02 \pm 20.05$ & $36.62 \pm 14.73$ & $40.62 \pm 28.09$ \\
\hline RV PRSW (mm Hg) & $11.66 \pm 1.86$ & $12.38 \pm 3.76$ & $20.56 \pm 14.49$ & $25.79 \pm 21.68$ \\
\hline$r^{2}$ & 0.99 & 0.98 & 0.93 & 0.83 \\
\hline $\mathrm{V}_{500}(\mathrm{~mL})$ & $53.55 \pm 7.63$ & $59.31 \pm 19.38$ & $66.41 \pm 32.68$ & $61.05 \pm 22.94$ \\
\hline
\end{tabular}

$R V$, Right ventricle; $V_{40}$, volume intercept when right ventricular systolic pressure is $40 \mathrm{~mm} \mathrm{Hg} ; V_{300^{\prime}}$ volume intercept when dp/dt ${ }_{\max }$ is $300 \mathrm{~mm} \mathrm{Hg} / \mathrm{s} ; V_{500}$ volume intercept when stroke work is $500 \mathrm{~mm} \mathrm{Hg} / \cdot \mathrm{mL}$.

${ }^{*} P=.01$ versus baseline.

$\dagger P<.05$ versus saline.

From the pressure-volume loops presented in Figure 3, one might suspect the presence of tricuspid regurgitation after PAB because of the lack of an isovolumic phase during early systole and ejection of the right ventricle started before the pulmonary arterial end-diastolic pressure was reached. This could explain the small but nonsignificant increase in the right ventricular end-diastolic volume and the lower right ventricular peak systolic pressure recorded at restudy compared with that recorded acutely after banding. The increase in central venous pressure seen in our study would also be consistent with tricuspid regurgitation. Despite this, pressure-volume analysis describes global pump function and is relatively independent of preload, ${ }^{28}$ which is one of the valuable benefits in pressure-volume analysis. However, the stroke volume, and hence ventricular output measured by the conductance catheter, will be overestimated by including the volume of blood that is ejected into the right atrium. Thus, the true forward cardiac output might have remained unchanged or even decreased in our experiment. The latter is unlikely because the left atrial pressure remained unchanged after the banding procedure.

The limitations of our study include the following. First, we have not, in the present study, examined the morphologic or molecular markers to validate the physiologic changes.

Second, in the present study we did not quantify the amount of right ventricular hypertrophy caused by the effect of banding alone. However, the right ventricular/left ventricular wall thickness ratio for the 2 groups listed in Table 2 suggested that there was a moderate degree of right ventricular hypertrophy produced in our current model. ${ }^{29,30}$

Third, the left ventricular systolic pressure, as reflected by the arterial systolic pressure, at all 3 time points was lower than what would normally be expected in sheep. This could be due to the anesthetic conditions causing vasodilatation. In an attempt not to hemodilute the circulating blood or to cause excess ventricular distention, no bolus volume infusion was attempted. This regimen was used for all animals, and any hemodynamic effect would have affected both groups of animals equally. However, the changes in right ventricular pressure in response to $\mathrm{PAB}$ could be underestimated as a result of interventricular interaction.

In conclusion, we have demonstrated that simultaneous treatment with clenbuterol, a $\beta_{2}$-adrenergic receptor agonist, during $6 \frac{1}{2}$ weeks of PAB improves right ventricular systolic function with no detrimental hemodynamic effects. This has important implications in various clinical settings, particularly in the training of the left ventricle in operations for certain types of congenital heart disease. The present study and other previous reports ${ }^{14,15}$ challenge the current notion that any chronic catecholamine stimulation is deleterious to the heart. On the basis of the fact that most of the toxic effects of $\beta$-adrenergic stimulation appears to be mediated largely by the $\beta_{1}$-adrenergic receptors, ${ }^{31}$ we speculate that concurrent use of $\beta_{2}$-adrenergic receptor agonist, such as clenbuterol, together with a selective $\beta_{1}$-adrenergic receptor blocker could be beneficial in certain clinical settings.

We thank Dr M. Al-Obaidi, Dr G. Carr-White, and Dr H. Khan for their contributions to the preparation of this manuscript and Boehringer-Ingleheim, UK, for generously supplying the clenbuterol used in this study.

\section{References}

1. Yacoub MH, Radley-Smith R, Maclaurin R. Two-stage operation for anatomical correction of transposition of the great arteries with intact interventricular septum. Lancet. 1977;1:1275-8.

2. Jonas RA, Giglia TM, Sanders SP, Wernovsky G, Nadal-Ginard B, Mayer JE Jr, et al. Rapid, two-stage arterial switch for transposition of the great arteries and intact ventricular septum beyond the neonatal period. Circulation. 1989;80:I-203-8.

3. Mee RB. Severe right ventricular failure after Mustard or Senning operation: two-stage repair-pulmonary artery banding and switch. $J$ Thorac Cardiovasc Surg. 1986;92:385-90.

4. Chang AC, Wernovsky G, Wessel DL, Freed MD, Parness IA, Perry 
SB, et al. Surgical management of late right ventricular failure after Mustard or Senning repair. Circulation. 1992;86:II-140-9.

5. Kirjavainen M, Happonen JM, Louhimo I. Late results of Senning operation. J Thorac Cardiovasc Surg. 1999;117:488-95.

6. Lorenz CH, Walker ES, Graham TP Jr, Powers TA. Right ventricular performance and mass by use of cine MRI late after atrial repair of transposition of the great arteries. Circulation. 1995;92:II-233-9.

7. Levy D. Left ventricular hypertrophy: epidemiological insights from the Framingham Heart Study. Drugs. 1988;35:1-5.

8. Takahashi Y, Nakano S, Shimazaki Y, Kadoba K, Taniguchi K, Sano T, et al. Echocardiographic comparison of postoperative left ventricular contractile state between one- and two-stage arterial switch operation for simple transposition of the great arteries. Circulation. 1991;84:III-180-6.

9. Boutin C, Wernovsky G, Sanders SP, Jonas RA, Castaneda AR, Colan SD. Rapid two-stage arterial switch operation: evaluation of left ventricular systolic mechanics late after an acute pressure overload stimulus in infancy. Circulation. 1994;90:1294-303.

10. Bersohn MM, Scheuer J. Effects of physical training on end-diastolic volume and myocardial performance of isolated rat hearts. Circ Res. 1977;40:510-6.

11. Wong K, Boheler KR, Bishop J, Petrou M, Yacoub MH. Clenbuterol induces cardiac hypertrophy with normal functional, morphological and molecular features. Cardiovasc Res. 1998;37:115-22.

12. Petrou M, Wynne DG, Boheler KR, Yacoub MH. Clenbuterol induces hypertrophy of the latissimus dorsi muscle and heart in the rat with molecular and phenotypic changes. Circulation. 1995;92:II-483-9.

13. Wong K, Boheler KR, Petrou M, Yacoub MH. Pharmacological modulation of pressure-overload cardiac hypertrophy: changes in ventricular function, extracellular matrix, and gene expression. Circulation. 1997;96:2239-46.

14. Liggett SB, Tepe NM, Lorenz JN, Canning AM, Jantz TD, Mitarai S, et al. Early and delayed consequences of beta(2)-adrenergic receptor overexpression in mouse hearts: critical role for expression level. Circulation. 2000;101:1707-14.

15. Milano CA, Allen LF, Rockman HA, Dolber PC, McMinn TR, Chien $\mathrm{KR}$, et al. Enhanced myocardial function in transgenic mice overexpressing the beta 2-adrenergic receptor. Science. 1994;264:582-6.

16. Turki J, Lorenz JN, Green SA, Donnelly ET, Jacinto M, Liggett SB. Myocardial signaling defects and impaired cardiac function of a human beta 2-adrenergic receptor polymorphism expressed in transgenic mice. Proc Natl Acad Sci U S A. 1996;93:10483-8.

17. Baan J, van der Velde ET, de Bruin HG, Smeenk GJ, Koops J, van Dijk $\mathrm{AD}$, et al. Continuous measurement of left ventricular volume in animals and humans by conductance catheter. Circulation. 1984;70:812-23.

18. Dickstein ML, Yano O, Spotnitz HM, Burkhoff D. Assessment of right ventricular contractile state with the conductance catheter technique in the pig. Cardiovasc Res. 1995;29:820-6.
19. Brookes CI, White PA, Bishop AJ, Oldershaw PJ, Redington AN, Moat NE. Validation of a new intraoperative technique to evaluate load-independent indices of right ventricular performance in patients undergoing cardiac operations. J Thorac Cardiovasc Surg. 1998;116:468-76.

20. de Vroomen M, Cardozo RH, Steendijk P, van Bel F, Baan J. Improved contractile performance of right ventricle in response to increased RV afterload in newborn lamb. Am J Physiol Heart Circ Physiol. 2000;278:H100-5.

21. Baan J, Van der Velde ET. Sensitivity of left ventricular end-systolic pressure-volume relation to type of loading intervention in dogs. Circ Res. 1988;62:1247-58.

22. van der Velde ET, Burkhoff D, Steendijk P, Karsdon J, Sagawa K, Baan J. Nonlinearity and load sensitivity of end-systolic pressurevolume relation of canine left ventricle in vivo. Circulation. 1991;83:315-27.

23. Little WC, Cheng CP, Mumma M, Igarashi Y, Vinten-Johansen J, Johnston WE. Comparison of measures of left ventricular contractile performance derived from pressure-volume loops in conscious dogs. Circulation. 1989;80:1378-87.

24. Lambertz H, Meyer J, Erbel R. Long-term hemodynamic effects of prenalterol in patients with severe congestive heart failure. Circulation. 1984;69:298-305.

25. Olsen SL, Gilbert EM, Renlund DG, Taylor DO, Yanowitz FD, Bristow MR. Carvedilol improves left ventricular function and symptoms in chronic heart failure: a double-blind randomized study. $J \mathrm{Am}$ Coll Cardiol. 1995;25:1225-31.

26. Petrou M, Clarke S, Morrison K, Bowles C, Dunn M, Yacoub M. Clenbuterol increases stroke power and contractile speed of skeletal muscle for cardiac assist. Circulation. 1999;99:713-20.

27. Guldner NW, Klapproth P, Grobetaherr M, Stephan M, Rumpel E, Noel R, et al. Clenbuterol-supported dynamic training of skeletal muscle ventricles against systemic load: a key for powerful circulatory assist? Circulation. 2000;101:2213-9.

28. Suga H, Sagawa K, Shoukas AA. Load independence of the instantaneous pressure-volume ratio of the canine left ventricle and effects of epinephrine and heart rate on the ratio. Circ Res. 1973;32:314-22

29. Lange PE, Nurnberg JH, Sievers HH, Onnasch DG, Bernhard A, Heintzen PH. Response of the right ventricle to progressive pressure loading in pigs. Basic Res Cardiol. 1985;80:436-44.

30. Little WC, Badke FR, O'Rourke RA. Effect of right ventricular pressure on the end-diastolic left ventricular pressure-volume relationship before and after chronic right ventricular pressure overload in dogs without pericardia. Circ Res. 1984;54:719-30.

31. Engelhardt S, Hein L, Wiesmann F, Lohse MJ. Progressive hypertrophy and heart failure in beta1-adrenergic receptor transgenic mice. Proc Natl Acad Sci U S A. 1999;96:7059-64. 